\title{
Fluorescence of 8-(Phenylamino)-1-naphthalene-ammonium- sulfonate in Solvents of Different Polarity
}

\author{
S. H. Hüttenhain, W. Balzer, and R. Feldmann \\ Fraunhofer-Institut für Umweltchemie und Ökotoxikologie, Am Arberg, D-57392 Schmallenberg
}

Z. Naturforsch. 49a, 1087-1090 (1994); received May 31, 1994

The solvatochromic fluorescence properties of 8-(phenylamino)-1-naphthalene-ammoniumsulfonate (1) were investigated in 22 pure solvents of rising polarity. The measurements of both Stokes' shifts and intensities discriminated between protic and aprotic solvents. Fairly good linear correlation plots of the dependence could be obtained on neglection of the values of tert.-butanol, DMF and DMSO.

Key words: Solvatochromic fluorescence; 8-(Phenylamino)-1-naphthalene-sulfonate (8,1 ANS); Protic solvents; Aprotic solvents.

\section{Introduction}

The decrease of the fluorescence intensity and the bathochromic shift of the emission wavelength of 8 (Phenylamino)-1-naphthalene-ammoniumsulfate $(8,1$ ANS- $\left.\mathrm{NH}_{4}\right)(\mathbf{1})$ with increasing polarity of its environment are well known and have been used for biochemical analyses [1].

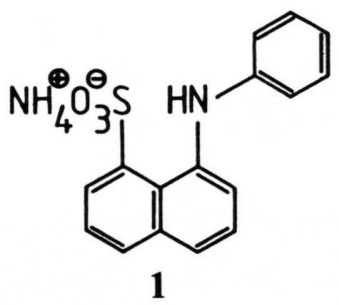

Fig. 1. 8-(Phenylamino)-1-naphthalene-ammoniumsulfonate (1).

Kosower and others intensively investigated this behaviour [2]. Looking for correlations of the fluorescence parameters of 1 with the solvent polarity, they mostly used homogeneous 1,4-dioxane/water mixtures of a defined $E_{\mathrm{T}}(30)$-value (the empirical solvent polarity parameter introduced by Reichardt and Dimroth $[3,4])$. Contrary to Kosower's views, the solvatochromic fluorescence of $\mathbf{1}$ has recently been found to be dependent on the hydrogen-bonding properties of the solvent $[5,6]$. Few data, however, have been re-

Reprint requests to the new address: Prof. Dr. Stefan H Hüttenhain, Fachhochschule Darmstadt, Fachbereich Chem. Techn., Hochschulestraße 2, D-64289 Darmstadt. ported on the fluorescence behaviour of 1 in pure solvents $[5,7,8]$. As far as we know, no systematic investigation of the fluorescence of $\mathbf{1}$ in pure solvents of rising polarity has been performed. Thus, to support the latest theory, we investigated the fluorescence intensity and Stokes' shift of $\mathbf{1}$ dissolved in pure solvents of defined $E_{\mathrm{T}}(30)$-values.

\section{Experimental}

1 was bought from Aldrich and purified by repeated chromatography on silica gel using toluene/ethanol $1: 1$ as eluant until the thin-layer chromatogram (TLC) showed one spot. The solvents (Aldrich, Merck, Fluka) were used without further purification when their purity was $\geq 99 \%$, otherwise they were distilled under $\mathrm{N}_{2}$. The absorption spectra were recorded on a Philips PU 8720 UV/VIS Spectrophotometer, the fluorescence spectra on a Perkin-Elmer MPF-3L fluorescence photometer. All measurements were carried out using a $10 \mu$ molar solution of 1 in the respective solvent. One sample was used to determine the maximum of the long-wavelength absorption band as well as the maximum of the emission band. With a second sample, the fluorescence intensity was measured as the hight of the emission band maximum. All measurements were carried out at $20^{\circ} \mathrm{C}$ except for methylacetamide, where the temperature was $40^{\circ} \mathrm{C}$. The fluorescence intensities were related to that of a sample dissolved in pure 1,4-dioxane, which was set equal to 1000 . The corresponding $\Delta \bar{v}$ values were calculated according to $[9]: \Delta \bar{v}=1 / \lambda_{\mathrm{Abs}}-1 / \lambda_{\mathrm{Em}}$. 
Fig. 2. Plot of the fluorescence intensity of 1 versus the polarity parameter $E_{\mathrm{T}}(30)$ of different solvents. For numbers see Table 1 . $\otimes=$ aprotic solvents, $\boldsymbol{\Delta}=$ protic solvents.

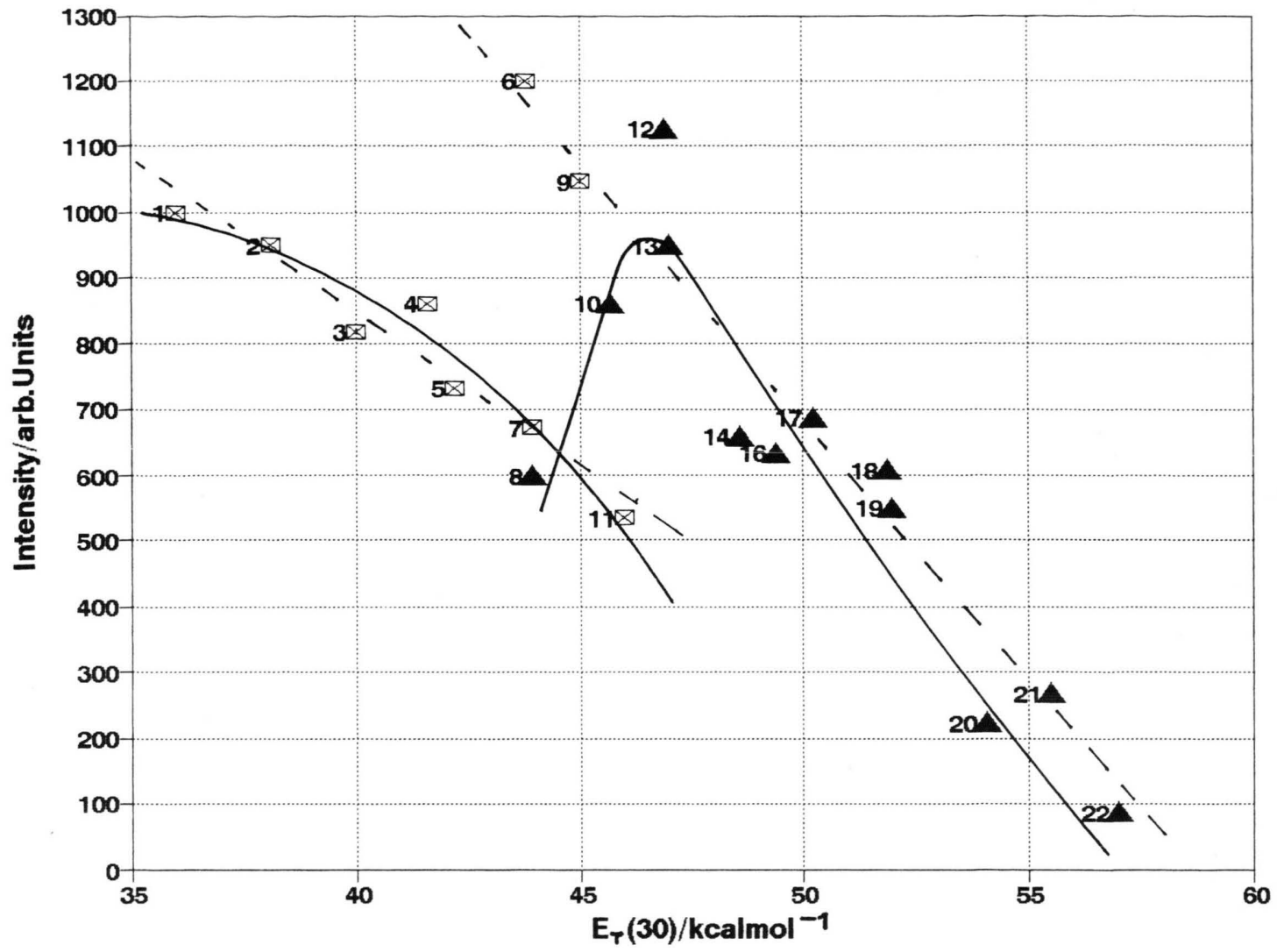

Table 1. Fluorescence properties of $\mathbf{1}$ in solvents of different polarity. $E_{\mathrm{T}}(30)=$ polarity parameter of C. Reichardt, $\lambda_{\text {Exc }}$, $\lambda_{\mathrm{Em}}=$ excitation and emission wavelength, $I=$ fluorescence intensity, $\Delta \bar{v}=$ Stokes' shift.

\begin{tabular}{|c|c|c|c|c|c|c|}
\hline & Solvents & $\frac{E_{\mathrm{T}}(30)}{\mathrm{kcal} / \mathrm{mol}}$ & $\frac{\lambda_{\text {Exc }}}{\mathrm{nm}}$ & $\frac{\lambda_{\mathrm{Em}}}{\mathrm{nm}}$ & $\frac{I}{\text { arb.units }}$ & $\frac{\Delta \bar{v}}{\mathrm{~cm}^{-1}}$ \\
\hline 1 & Dioxan & 30.0 & 378 & 464 & 1000 & 4.90 \\
\hline 2 & Ethylacetate & 38,1 & 376 & 460 & 950 & 4.86 \\
\hline 3 & Methylacetate & 40.0 & 374 & 458 & 820 & 4.90 \\
\hline 4 & Triacetin & 41.6 & 376 & 463 & 862 & 5.00 \\
\hline 5 & Acetone & 42.2 & 372 & 458 & 733 & 5.05 \\
\hline 6 & DMF & 43.8 & 373 & 458 & 1200 & 4.98 \\
\hline 7 & Acetanhydride & 43.9 & 374 & 464 & 672 & 5.19 \\
\hline 8 & tert.-Butanol & 43.9 & 376 & 466 & 600 & 5.14 \\
\hline 9 & DMSO & 45.0 & 375 & 464 & 1047 & 5.11 \\
\hline 10 & 3-Pentanol & 45.7 & 377 & 462 & 863 & 4.88 \\
\hline 11 & Acetonitrile & 36.0 & 369 & 464 & 534 & 5.55 \\
\hline 12 & Cyclohexanol & 46.9 & 379 & 460 & 1127 & 4.65 \\
\hline 13 & 3-Methylbutanol & 47.0 & 378 & 459 & 950 & 4.67 \\
\hline 14 & Isopropanol & 48.6 & 376 & 460 & 659 & 4.86 \\
\hline 15 & 1-Pentanol & 49.1 & 377 & 462 & 770 & 4.88 \\
\hline 16 & Ethylacetoacetat & 49.4 & 375 & 464 & 634 & 5.11 \\
\hline 17 & 1-Butanol & 50.2 & 378 & 460 & 687 & 4.72 \\
\hline 18 & Ethanol & 51.9 & 374 & 464 & 609 & 5.19 \\
\hline 19 & Methylacetamide & 52.0 & 375 & 468 & 550 & 5.30 \\
\hline 20 & Methylformamide & 54.1 & 374 & 474 & 222 & 5.64 \\
\hline 21 & Methanol & 55.5 & 374 & 472 & 269 & 5.55 \\
\hline 22 & Glycerol & 57.0 & 376 & 482 & 87 & 5.85 \\
\hline
\end{tabular}


Fig. 3. Plot of the Stokes' shift of 1 versus the polarity parameter $E_{\mathrm{T}}(30)$ of different solvents. For numbers see Table 1 . $\bigotimes=$ aprotic solvents, $\Delta=$ protic solvents.

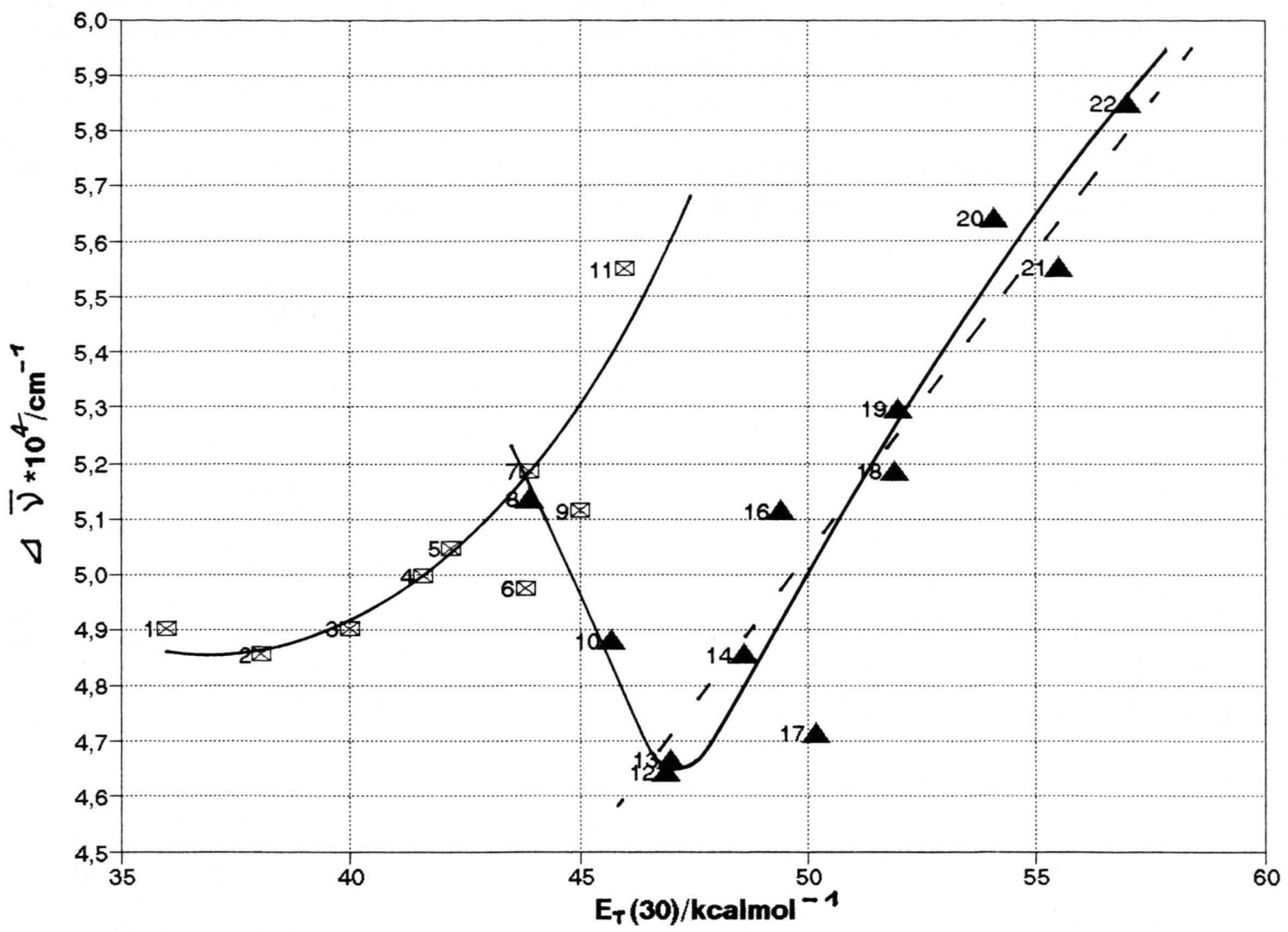

\section{Results and Discussion}

There exist protic and aprotic solvents over a wide range of polarities. For both groups, we have chosen solvents covering the whole polarity scale. Table 1 lists these media together with their polarity $E_{\mathrm{T}}(30)$ and the corresponding excitation and emission maximum of 1 dissolved therein.

Figure 2 shows the fluorescence intensity of 1 versus $E_{\mathrm{T}}(30)$ of the used solvents and Fig. 3 the corresponding Stokes' shift.

The protic solvents show a distinct maximum of the fluorescence intensity at $E_{\mathrm{T}}(30)=46.0 \mathrm{kcal} / \mathrm{mol}$ and a corresponding minimum of the Stockes' shift. Looking for the fluorescence intensities, dimethylformamide (DMF) and dimethylsulfoxide (DMSO) are not near the curve of the other aprotic solvents but seem to fit more to the protic-solvent curve. But whereas DMF and DMSO show "protic" behaviour as to the intensities, their Stokes' shifts are close to the aprotic line. As

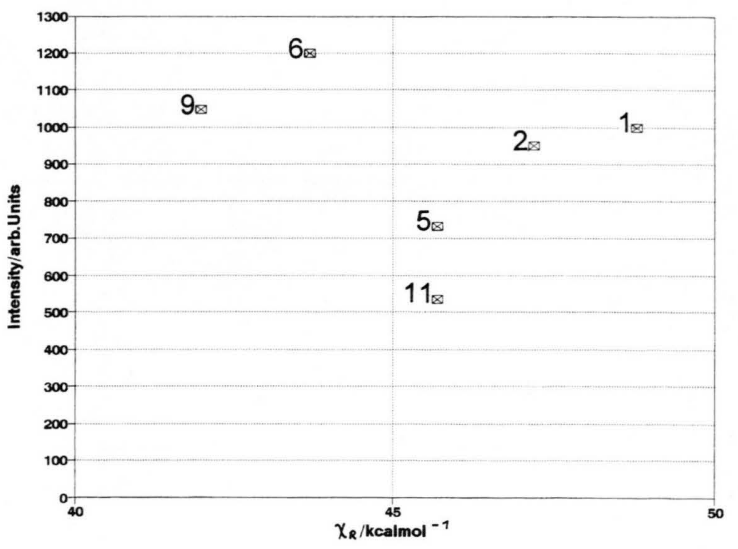

Fig. 4. Plot of fluorescence intensity of 1 versus the polarity parameter $\chi_{\mathrm{R}}$ of different solvents. For numbers see Table 1.

these two solvents are very polarizable, the correlation of their fluorescence intensities with the solvent polarity $\chi_{\mathrm{R}}$ of Brooker, which is more sensitive to polarisation than to orientation effects $[10,11]$, was tested. 
However, Figure 4 shows that the correlation does not become better.

Besides these two solvents, the fluorescence properties of $\mathbf{1}$ in tert.-butanol are quite different from what was expected. This solvent seems to behave as an aprotic one.

Neglecting theses three exceptions, one finds linear correlations for the remaining measurements of the fluorescence intensity with $r=0.9635$ for the aprotic solvents without DMF and DMSO, and $r=0.9448$ for the protic ones without tert.-butanol (Fig. 2, dashed lines). In case of the Stokes' shifts, the aprotic solvents do not yield a linear plot. The calculation of

[1] A. Azzi, Q. Rev. Biophys. 8, 237 (1975).

[2] E. M. Kosower, J. Amer. Chem. Soc. 107, 1114 (1985), and ref. cited.

[3] C. Reichardt, Angew. Chem. 91, 119 (1979); Angew. Chem., Int. Ed. Engl. 18, 98 (1979).

[4] C. Reichardt, Solvent Effects in Organic Chemistry, Verlag Chemie, Weinheim 1979.

[5] G. L. Mendz, R. J. Vandenberg, and S. B. EasterbrookSmith, Magn. Reson. Chem. 28, 104 (1990).

[6] S. H. Hüttenhain and W. Balzer, Z. Naturforsch. 48a, 709 (1993). the linear correlation of the protic solvents (excepting tert.-butanol) results in $r=0.9188$ (Fig. 3, dashed line).

Although no clear linear correlation of the fluorescence intensity or Stokes' shift of $\mathbf{1}$ in neither the protic nor the aprotic solvents is found, it seems obvious from the different plots that the solvatochromic fluorescence of $\mathbf{1}$ is mainly influenced by the protic character of the solvent.

Presently, no interpretation can be given for the fact that the possible linear correlation lines for the intensity meet for $I \rightarrow 0$ in a common polarity value of $E_{\mathrm{T}}(30)=58.4 \mathrm{kcal} / \mathrm{mol}$. A substance specific value of 1 might be proposed for that.

[7] D. C. Turner and L. Brand, Biochemistry 7, 3381 (1968).

[8] D. Huppert, H. Kanety, and E. M. Kosower, Faraday Discuss. Chem. Soc. 74, 161 (1982).

[9] J. R. Lakowicz, Principles of Fluorescence Spectroscopy, Plenum Press, New York 1983.

[10] L. G. S. Brooker, A. C. Craig, D. W. Heseltine, D. W. Jenkins, and L. L. Lincoln, J. Amer. Chem. Soc. 87, 2443 (1965).

[11] H. Langhals, Z. Phys. Chem. 127, 45 (1981). 